\title{
ВЛИЯНИЕ ИНВЕСТИЦИОННЫХ РЕСУРСОВ НА РАЗВИТИЕ ИННОВАЦИОННЫХ ПРОЦЕССОВ В ЖИВОТНОВОДСТВЕ
}

\author{
(c) 2019 Васильченко Марианна Яковлевна \\ кандидат экономических наук, старший научный сотрудник \\ Институт аграрных проблем Российской академии наук, Россия, Саратов \\ E-mail: mari.vasil4enko@yandex.ru
}

Исследовано влияние инвестиционных ресурсов на развитие инновационных процессов в отраслях животноводства. Выявлена взаимосвязь «уровня достаточности» инвестирования сельскохозяйственного производства с процессом распространения инноваций в отраслях животноводства. Осуществлен критический анализ используемых инструментов инвестиционной поддержки, обоснована необходимость стимулирования распространения инноваций с учетом региональных особенностей и институциональной структуры.

Ключевые слова: инвестиционные ресурсы, инновационные процессы, животноводство, механизмы государственной поддержки

\section{Введение}

Важным условием экономического роста и повышения конкурентоспособности в агропромышленном комплексе выступает уровень обеспеченности инвестиционными ресурсами, стимулирующими процесс инновационной структурной трансформации. Среди теорий структурных трансформаций наибольшее распространение получили: теория динамического развития Э. Домара, теория структурных изменений Й. Шумпетера, институциональная теория структурных трансформаций Д. Норта, теория «трехфазного развития» Х. Ченери, А. Страут. В теории динамического развития Э. Домара обосновывается необходимость импорта капитала и либерализации условий его привлечения в странах со слабым развитием экономики, недостаточным количеством финансовых ресурсов и реальных сбережений. Теория «трехфазного развития» слаборазвитой экономики Х. Ченери, А. Страут объясняет структурную трансформацию воздействием ряда факторов, среди которых немаловажное значение имеет накопление капитала. «Трехфазное развитие» страны включает период максимального поглощения экономикой инвестиционных ресурсов с целью выравнивания средней склонности к сбережениям и нормы инвестирования; период нехватки инвестиций, требующий внешнего притока капитала; период экономического роста в результате импортозамещения и наращивания экспорта, определяющий процесс структурной трансформации экономики [1]. Таким образом, перераспределение инвестиционных ресурсов имеет следствием структурную перестройку экономики.

Повышение эффективности использования инвестиций обусловливает необходимость взаимосвязи инновационных и инвестиционных процессов на региональном уровне, причем инвестиции должны осуществляться по всей цепочке нововведений. Оптимальная стратегия должна отражать меры, направленные на повышение рейтинга региона, институциональные меры по реализации инновационной политики, совершенствованию территориального размещения производительных сил и другие актуальные мероприятия [2].

Российскими учеными отмечается важная роль современных инвестиционно-инновационных инструментов, моделей и механизмов, направленных на повышение конкурентоспособности предприятий аграрного сектора и расширение экспортного потенциала, причем для решения проблемы инновационной активности хозяйствующих субъектов необходима разработка целенаправленной аграрной инновационной политики, определяющей цели, задачи и механизмы реализации с учетом имеющихся приоритетов [3]. Поставленная задача может быть реализована при условии гармонизации федеральной и региональной политики [4], причем механизм государственной поддержки инновационного воспроизводства в сельском хозяйстве должен стимулировать процесс смены технологических укладов. Вышесказанное обу- 
словливает необходимость совершенствования инвестиционной политики на уровне субъектов РФ, важнейшим направлением которой является стимулирование притока инвестиций в приоритетные подотрасли сельского хозяйства.

Цель настоящего исследования заключается в выявлении влияния инвестиционных ресурсов на развитие инновационных процессов в отраслях животноводства, обосновании предложений по повышению эффективности использования инвестиционной поддержки.

\section{Методика исследования.}

В качестве метода исследования использованы методические подходы автора к оценке процесса диффузии инноваций на региональном уровне с помощью коэффициентов инновационности производства различных видов животноводческой продукции. На основе статистического анализа выделены группы регионов РФ, характеризующихся различным уровнем обеспеченности инвестициями в основной капитал, направленных на развитие сельского хозяйства. Реализовывалась гипотеза о взаимосвязи «уровня достаточности» инвестирования сельскохозяйственного производства с процессом распространения инноваций в отраслях животноводства.

\section{Результаты исследования.}

В агропромышленном комплексе России прослеживается ярко выраженная региональная дифференциация уровня обеспеченности инвестициями в основной капитал. В 2017 г. на долю Центрального федерального округа приходилось 43,5\% от общего объема инвестиций в основной капитал, направленных на развитие сельского хозяйства; на долю Приволжского федерального округа - 17,8\%. Необходимо отметить наличие региональной дифференциации в обеспеченности инвестициями на протяжении ряда лет (рисунок 1). Доля инвестиций в основной капитал по сельскому хозяйству в общем объеме инвестиций также имеет значительные колебания в разрезе регионов. Например, в 2017 г. при среднем значении вышеуказанного показателя по России 2,35\% максимальные значения показателя достигнуты в Центральном $(3,9 \%)$ и Северо-Кавказском $(4,3 \%)$ федеральных округах; наименьшие значения - в Уральском (0,62\%), Дальневосточном (0,99\%), Северо-Западном (1\%) федеральных округах.

Высокая инвестиционная активность наблюдается в республиках Крым и Саха (Якутия), Кемеровской области; инвестиции в основной капитал осуществляют свыше 90\% организаций. Низкую инвестиционную активность имеют такие регионы, как Республика Ингушетия (инвестиционной деятельностью занимаются 29\% организаций; Республика Дагестан (37\%), Республика Алтай (48\%), Забайкальский край (56\%), Калининградская (69\%) и Тверская (70\%) области [5].

В ходе исследования взаимосвязи между

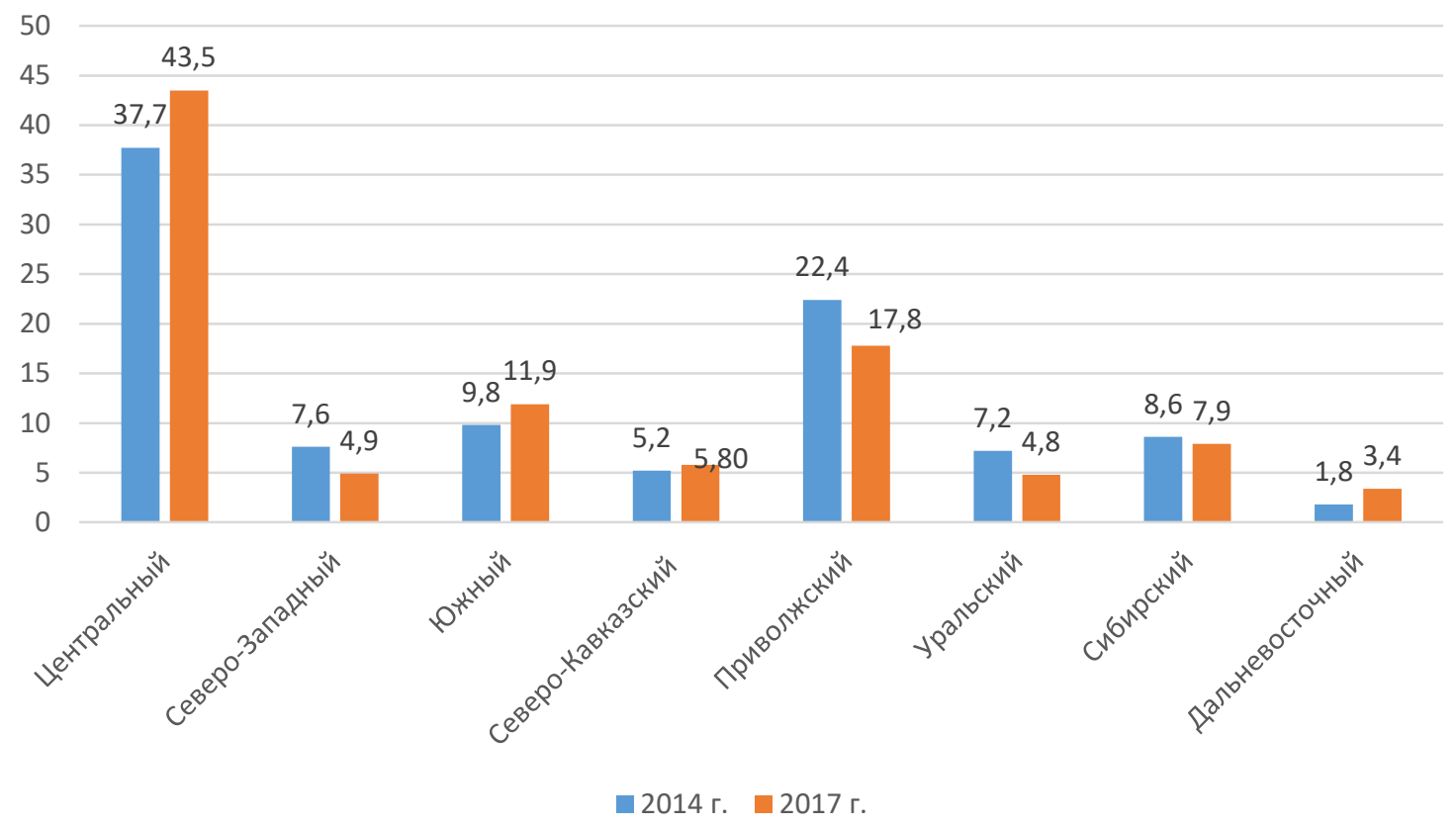

Рисунок 1. Распределение инвестиций в основной капитал, направленных на развитие сельского хозяйства, по федеральным округам,\% 
уровнем обеспеченности инвестициями в основной капитал сельского хозяйства и развитием инновационных процессов в качестве базовых были выбраны подотрасли скотоводство и свиноводство, поскольку в последние годы в результате модернизации и технического перевооружения здесь наиболее активно осуществляется процесс распространения инноваций. По данным официальной статистики в 2017 г. ввод в действие сельскохозяйственных мощностей для крупного рогатого скота составил 275,1 тыс. скотомест (увеличение по сравнению с 2014 г. в 2,3 раза); для свиней - 1335,2 тыс. скотомест (увеличение по сравнению с 2014 г. в 1,7 раза) [6].

Для расчетов использовался информационный массив, включающий 72 региона-субъекта РФ. С целью устранения несопоставимости информации по отдельным показателям из анализируемой совокупности были исключены автономные округа, Магаданская область, Еврейская автономная область; города Москва, Санкт-Петербург, Севастополь, а также Республика Крым. В основу выделения групп регионов был положен показатель «Инвестиции в основной капитал на развитие сельского хозяйства в расчете на 1000 га сельскохозяйственных угодий. Полагаем, что данный показатель наиболее полно отражает обеспеченность инвестиционными ресурсами и позволяет охарактеризовать их достаточность для осуществления инновационного воспроизводства. В первую группу были включены регионы с показателем обеспеченности инвестиционными ресурсами до 1 млн. руб. на 1000 га сельскохозяйственных угодий (28 регионов); во вторую - с показателем от 1 до 3 млн.руб. (26 регионов); в третью - с показателем свыше 3 млн. руб. (18 регионов). Среднее значение по группам составляет: первая группа - 459,7 тыс. руб. (что значительно ниже среднероссийского уровня 1687,9 тыс. руб.); вторая группа - 1699,1 тыс. руб. (незначительное превышение среднероссийского уровня); третья группа - 5200,5 тыс. руб. (существенное превышение среднероссийского уровня). Таким образом, если принять за пороговый уровень среднероссийский показатель (1688 тыс. руб. в расчете на 1000 га сельскохозяйственных угодий), выделенные группы можно охарактеризовать как недоинвестированнную (первая); достаточную (вторая)

и сверхвысокую (третья). Например, в третьей группе наибольшая обеспеченность инвестициями в основной капитал по сельскому хозяйству в 2017 году достигнута в таких регионах как Московская (8217,4 тыс. руб.), Калужская (9265,7 тыс. руб.), Мурманская (10699,2 тыс. руб.) области. Кроме того, характерной особенностью третьей группы является высокая доля инвестиций в сельское хозяйство по отношению к общему объему инвестиций $(5,1 \%)$. В среднем по России этот показатель равен 2,35\%. В первых двух группах доля инвестиций в сельское хозяйство составляет, соответственно, $1,55 \%$ и 1,66\%.

Для выявления взаимосвязи между уровнем обеспеченности инвестициями в основной капитал сельского хозяйства и развитием инновационных процессов в животноводстве применялись частные индикаторы инновационности производства мяса крупного рогатого скота, свиней и молока. Вышеупомянутые индикаторы определялись на основе нормированного метода как отношение продуктивности животных к её пороговому уровню, который может достигаться при условии использования инновационных ресурсов животных (племенного скота), а также инновационных технологий содержания и кормления скота. Результаты расчетов представлены на рисунке 2.

Результаты исследования подтвердили гипотезу о наличии определенной взаимосвязи между инвестициями и распространением инноваций в отраслях животноводства. Самые низкие показатели инновационности производства мяса КРС, свиней и молока - в «недоинвестированной» первой группе регионов; наиболее значимые - в «сверхвысокой» третьей группе. Таким образом, в современных условиях нехватки бюджетных средств остро стоит вопрос как о достаточности объема выделяемых инвестиций в отрасли агропромышленного комплекса, так и об эффективности государственной поддержки инвестиций [7]. Вполне очевидно, что механизмы инвестиционной поддержки должны стимулировать процессы распространения инноваций в отраслях и продуктовых цепочках. На это обстоятельство обращает внимание отдельные ученые, отмечая необходимость внедрения инвестиций по всей цепочке нововведений [8]. Подобное положение следует учитывать при формировании стратегии регионального развития. Недостаточный охват мерами государственной поддержки инвестиций в региональном разрезе подтверждается следующими данными. Из общей суммы субсидий на возмещение части прямых понесенных затрат на создание и модерни- 


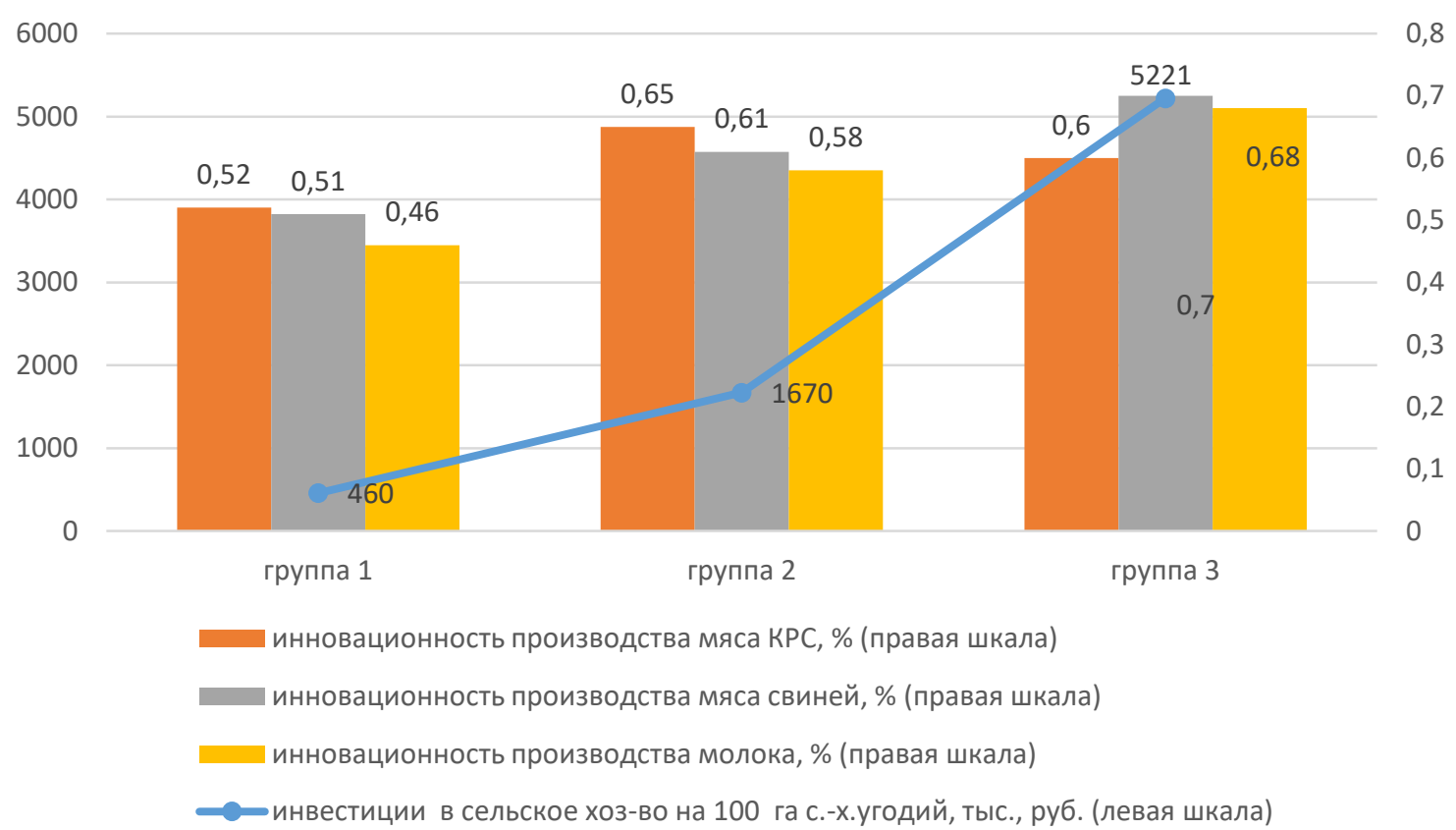

Рисунок 2. Влияние обеспеченности инвестициями в основной капитал, направленных на развитие сельского хозяйства, на инновационность производства животноводческой продукции по группам регионов РФ (2017 г.)

зацию объектов АПК (КАПЕКСов) по состоянию на 2017 год в пяти регионах Черноземной зоны России было сконцентрировано $47 \%$, а на регионы Северного Нечерноземья приходилось только 7\%. Характерно, что концентрация государственной поддержки прослеживается не только в конкретных регионах, но и в разрезе крупных хозяйств холдингового типа, причем нередко реализация проектов в животноводстве не ориентирована на региональные и отраслевые особенностей [9].

Как показывает статистика, такие формы государственной поддержки как КАПЕКСы и льготные кредиты пока имеют ограниченный ареал применения. Анализ состояния инвестиционной поддержки в молочном скотоводстве России показал, что в 2018 г. субсидии на льготное кредитование не получили 14 российских регионов (в том числе Саратовская, Волгоградская, Курганская области, Республика Татарстан). Субсидиями на возмещение части прямых затрат на создание и модернизацию объектов в этом же периоде не воспользовались 43 региона. Особенно проблематично получение инвестиционной поддержки малыми и средними сельскохозяйственными предприятиями.

Одним из основных направлений повышения инвестиционной активности средних по размерам производителей молока в регионах с невысоким агроклиматическим потенциалом является расширение для них возможности приобретения техники и оборудования с высокой инновационной составляющей; осуществления поэтапной модернизации производства. Усиление инновационного вектора инвестиционной поддержки регионов предопределяет необходимость стимулирования приобретения сельскохозяйственными товаропроизводителями таких инновационных ресурсов, как техника и оборудование с высокой инновационной составляющей. Подобная мера используется в случае импорта при отсутствии российских аналогов. По сравнению с поддержкой КАПЕКСов и инвестиционного кредитования прямое субсидирование сельскохозяйственных товаропроизводителей, приобретающих технику и оборудование, рассматривается российскими учеными в качестве одной из приоритетных форм поддержки, способствующей повышению эффективности инновационно-инвестиционного развития АПК. На эти цели должны выделяться средства как из региональных бюджетов, так и из федерального бюджета, причем эта мера будет в наибольшей степени востребована малыми и средними предприятиями в регионах с низким агроклиматическим потенциалом [10].

Следует отметить, что важным условием повышения эффективности использования инвестиционных ресурсов выступает совершенствование систем поручительства и залогового 
обеспечения. В отдельных российских регионах имеется положительный опыт использования подобных мер. Например, в Новосибирской области гарантийный фонд выдает поручительства до $70 \%$ займа по кредитным договорам потребительским кооперативам, малым и средним сельскохозяйственным предприятиям, крестьянским (фермерским) хозяйствам [11].
Исследования показали, что развитие инновационных процессов в агропромышленном комплексе определяется не только обеспеченностью инвестиционными ресурсами, но и наличием эффективных механизмов инвестиционной поддержки, стимулирующих распространение инноваций с учетом региональных особенностей и институциональной структуры производства.

\section{Библиографический список}

1. Chenery H.B. The structuralist approach to development policy // American association Papers and Proceedings. 1975 - № $65-$ P. 310-316.

2. Строева О.А. Инвестиционно-инновационная стратегия перехода региональной экономической системы в режим устойчивого экономического роста // Вестник ОрелГИЭТ, 2010. № 1(11). С. 101-106.

3. Ушачев И.Г., Колесников А.В., Чекалин В.С. Развитие инноваций - важнейшая составляющая аграрной политики России // АПК: экономика, управление. 2019. № 5. С. 22-31.

4. Санду И., Крутиков В. Гармонизация региональной и федеральной политики в условиях внешнеэкономических вызовов // Экономика сельского хозяйства России. 2019. № 5. С. 11-16.

5. Инвестиции в России: статистический сборник. - Режим доступа: https://www.gks.ru.

6. Агропромышленный комплекс России в 2017 году: статистический сборник.-Режим доступа: https://www. mcx.ru.

7. Андрющенко С.А., Васильченко М.Я. Показатели уровня обеспеченности инвестициями роста производства в агропромышленном комплексе // Научное обозрение: теория и практика. 2015. № 4. С. 49-57.

8. Трошин А., Санду И., Дощанова А. Инновационно-инвестиционная компонента в стратегии развития региона // АПК: экономика, управление. 2018. № 2.-С. 29-35.

9. Суровщев В.Н. Формирование «молочного пояса» как фактор реализации экспортного потенциала АПК России.- Режим доступа: https://www.dairynews.ru/news/formirovanie-molochnogo-poyasa-kak-faktor-realizats. html.

10. Суровщев В.Н. Стратегия господдержки инвестиций в АПК: приоритеты и эффективность.- Режим доступа: https://www.dairynews.ru/news/strategiya-gospodderzhki-investitsiy-v-apk-priorit.htm.l

11. Тю Л., Чиркова И. Совершенствование инвестиционной политики в сельском хозяйстве Сибири в современных условиях // АПК: экономика, управление. 2017. № 11. С. 62-71. 